\title{
Habilidades sociais e afetividade no contexto escolar: Perspectivas envolvendo professores e ensino-aprendizagem
}

\author{
Social skills and affectivity in the school context: Perspectives involving teachers and teaching-learning
}

\author{
Valéria Teixeira da Cunha Reis ${ }^{[a]}$, Mary Anne Rodrigues Prata ${ }^{[b]}$, Adriana Benevides Soares ${ }^{[c]}$
}

${ }^{[a]}$ Mestre em Psicologia Social pelo Centro Universitário UNIABEU, professora dos cursos de Pedagogia e Letras da UNIABEU, Rio de Janeiro, RJ - Brasil, e-mail: valeriatreis@gmail.com

${ }^{\left[{ }^{[b]}\right.}$ Mestre em Psicologia Social pela Universidade Salgado de Oliveira, Rio de Janeiro, RJ - Brasil, e-mail: maryanneprata@gmail.com

${ }^{[c]}$ Doutora em Psicologia Cognitiva pela Universidade Salgado de Oliveira (UNIVERSO), Rio de Janeiro, RJ - Brasil, e-mail: adribenevides@gmail.com

Recebido: $15 / 12 / 2010$ Received: $12 / 15 / 2010$

Aprovado: 13/04/2011 Approved: 04/13/2011

\section{Resumo}

A fase escolar está implicada na potencialização das capacidades afetivas, cognitivas e sociais do indivíduo. A escola é um aliado da família na socialização da criança, e o professor, modelo e mediador de experiências sociais. As interações do professor com o aluno são mediadas por crenças afetivas que influenciam o desempenho acadêmico e o desenvolvimento cognitivo e emocional desses alunos (Del Prette, Paiva \& Del Prette, 2005). A presente pesquisa tem como objetivo identificar as habilidades sociais de professores e as suas concepções a respeito da importância da afetividade na aprendizagem. Também é objeto deste estudo verificar se existe a relação entre os repertórios comportamentais apresentados e as concepções implícitas acerca da afetividade na aprendizagem. Participaram da pesquisa 70 professores que atuavam entre o ensino fundamental e o ensino médio. Foi aplicado nos professores o IHS - Del Prette (2001) e um questionário com quatro perguntas abertas relacionadas à interação afetiva professor-aluno na aprendizagem. Encontrou-se, como principais resultados, que os professores possuem um repertório rico em habilidades sociais e atribuem significativa importância à afetividade na aprendizagem, porém essas variáveis não se relacionam.

Palavras-chave: Habilidades sociais. Afetividade. Professores. Aprendizagem.

\begin{abstract}
The period in school is implicated in the empowerment of affective, cognitive and social abilities of the student. The school is a helper for the family in the socialization of the child and the teacher is the model and mediator in social experiences. The teacher's interactions with the student are mediated by affective beliefs that influence academic performance and cognitive and emotional developments of the student (Del Prette, Paiva \& Del Prette, 2005). This research aims to identify the social skills of teachers and their conceptions about the significance of affectivity in learning. Another goal of this research is to verify whether there is a relation between behavioral repertories presented and the implicit conceptions about affectivity in learning. Seventy teachers who worked between elementary school and high school levels participated in this research. The IHS - Del Prette (2001) has been applied to the teachers and also a questionnaire with four open questions related to an affective teacher-student learning interaction. The main results obtained
\end{abstract}


are that the teachers have a rich social abilities repertoire and that they attribute significant importance to affectivity in the learning process, even though these variables are not related to each other.

Keywords: Social skills. Affectivity. Teachers. Learning.

\section{Introdução}

A presente pesquisa tem como objetivo identificar as habilidades sociais de professores e as suas concepções acerca da importância da afetividade na aprendizagem. Também é objeto deste estudo verificar se existe relação entre os repertórios comportamentais apresentados e as concepções implícitas a respeito da afetividade na aprendizagem. Considerando que na fase escolar, a escola é um aliado da família na socialização das crianças, em que o professor é um mediador e modelo para ampliar a possibilidade de interações pessoais por meio de experiências afetivas (Soares, Naiff, Cardozo, Baldez \& Fonseca, 2009), é justificável conhecer como o professor concebe a relação entre afetividade e aprendizagem assim como verificar se professores habilidosos socialmente atribuem mais importância à afetividade como essencial à aprendizagem de que os professores menos habilidosos.

A afetividade pode ser produtiva tanto para o professor quanto para o aluno no processo de ensino-aprendizagem. Considerado como uma díade, o aluno-professor e o ensino-aprendizagem, é importante que o professor tenha com o aluno uma relação amistosa e impregnada de sentimentos positivos para que ocorra uma aprendizagem profícua (Mahoney e Almeida, 2005).

Segundo Del Prette, Paiva \& Del Prette, (2005) as relações do professor com o aluno são mediadas por crenças, sentimentos, motivações e habilidades. Todas estas variáveis influenciam no rendimento acadêmico e desenvolvimento cognitivo e emocional desses alunos. Conforme Loos e Sant'Ana (2007), a cognição e o afeto são duas variáveis que andam juntas no contexto da aprendizagem, pois a afetividade do indivíduo é desenvolvida a partir de vários componentes psicológicos e intelectuais. Neste contexto, a emoção se dá por meio das percepções cognitivas, pois para estes autores é pelas emoções que se encontram as motivações para construir um repertório intelectual.
Segundo Del Prette, Del Prette, Paiva e Fernandes (2005) as ideias atuais do significado do ensino vão além da transmissão de conhecimentos de forma passiva e são consideradas uma tarefa dinâmica que envolve orientar, promover e mediar o desenvolvimento de outras capacidades intelectuais e socioemocionais necessárias à aprendizagem dos diferentes conteúdos acadêmicos e ao desenvolvimento mais geral desse aluno. Para Escaraboto (2007), na relação do professor com o aluno existem questões que dificultam a aprendizagem do aluno. Por exemplo, quando o professor observa que alguns conseguem aprender e outros não, o professor pode colocar a sua prática em questão. Se esse professor estiver desmotivado, pode atribuir a responsabilidade do fracasso escolar exclusivamente ao aluno desconsiderando sua participação. A autora ressalta que reconhecer no aluno a sua individualidade talvez seja uma tarefa difícil para o professor, pois diversas condições sociais, econômicas e individuais do aluno podem influenciar em seu desempenho escolar. É necessário levar o aluno a uma motivação pela aprendizagem que vai além da simples atividade escolar. Desta forma, ele pode desenvolver e atingir o conhecimento.

Em um estudo feito por Del Prette, Del Prette, Garcia, Silva e Puntel (1998), foi verificado que, com o papel de mediador, o professor transmite o conhecimento para o aluno, assim como permite a observação de sua interação por meio das habilidades interpessoais. Cabe ao professor promover a coordenação das atividades educativas entre os alunos. A expressão afetiva do professor para com os alunos promove o incentivo e os motivam mais a participarem das aulas, podendo captar os conhecimentos veiculados em sala de aula. Para Leite e Tagliaferro (2005). a relação entre o professor e o aluno em sala de aula vai além de uma relação pedagógica. 0 professor desperta no aluno o interesse que transpassa as dimensões cognitivas e afetivas por meio de seu envolvimento com cada um deles. Ao estabelecer 
uma relação afetiva entre o professor e o aluno, reflete-se uma interação entre o conhecimento e as relações interpessoais que levam ao desenvolvimento mental e social do aluno.

De acordo com Del Prette e Martini (2002), para que seja clara a compreensão com relação ao tipo de habilidades que efetivamente contribui para preparação da vida, é preciso valorizar as habilidades assertivas e de enfrentamento. Problemas socioemocionais associados às dificuldades dos estudantes considerados tímidos ou muito agressivos podem ter sua causa no deficit nas chamadas habilidades de sobrevivência em classe. Esse deficit também pode ter relação com as dificuldades de aprendizagem e baixo rendimento escolar. Segundo Marturano e Loureiro (2003), durante a fase escolar o indivíduo faz uma seleção de suas experiências relacionais de acordo com o seu contexto histórico social e cultural organizando suas ações e transferindo para as suas vivências sociais. A importância de sua adaptação e interação com os outros na escola está nas relações que poderá desenvolver. Essa adaptação e interação podem proporcionar ao estudante habilidades sociais, visto que o modo como a criança se avalia pode contribuir para o seu desempenho escolar e consequentemente para sua interação com os demais, bem como à expressão de suas emoções negativas ou positivas. Estes mesmos autores atribuem importância à afetividade nesta fase, que pode ajudar as crianças nas interações escolares, sendo um agente motivador para aprender a enfrentar situações cotidianas, assim como para desenvolver a autoeficácia.

A tarefa dos professores em mediar o ensino e a aprendizagem do aluno não é fácil. Entretanto se o professor souber utilizar os instrumentos pedagógicos para levar os estudantes ao desenvolvimento dos processos cognitivos e sociais, estará proporcionando ao aluno a cidadania. 0 exercício das habilidades sociais possibilita o relacionamento com os outros em qualquer ambiente social. 0 aluno que exerce plenamente suas habilidades sociais poderá vir a ser uma pessoa com uma boa inserção social futura (Del Prette, Del Prette, Garcia, Silva \& Puntel, 1998). Segundo Del Prette e Del Prette (1997), os professores devem ter um conjunto de habilidades sociais que são importantes para a promoção da aprendizagem e desenvolvimento interpessoal dos alunos. Ter uma visão ampla do que está acontecendo com os alunos na sala de aula, saber mudar suas atitudes perante as dificuldades que os alunos possam apresentar, saber avaliar as potencialidades, expor suas opiniões e dar e receber feedback são comportamentos facilitadores da relação ensino-aprendizagem.

Para Del Prette, Del Prette e Correia (1992), a construção social do conhecimento mediado pelo professor depende, além da sua competência profissional, também de um repertório com um valor diferenciado de habilidades interpessoais para levar os seus alunos a conflitos sociocognitivos para que eles interajam positivamente diante de soluções desses conflitos. Segundo Assmann (1998), o conhecimento surge a partir do interesse do aluno pelo o que está sendo ensinado, e o professor terá que ter a habilidade de saber transmitir a esse aluno a informação valorizando e respeitando o aluno. Tal processo se desenvolve com desenvoltura quando o professor mostra afetividade, motivação em ensinar e habilidades sociais. 0 professor que saiba demonstrar afetividade e que consiga alcançar o aluno e a turma, consequentemente desenvolverá tanto as suas habilidades sociais como ajudará a desenvolver a dos alunos, apontando para uma relação de união e cooperação. No ambiente escolar a expressão dos sentimentos permite estabelecer uma ligação interpessoal mesmo quando não há uma relação intelectual (Wallon, 1996).

Para Mahoney e Almeida (2005), quando o professor promove nos alunos a integração dos conceitos afetivos (emoção, sentimento e paixão) no processo de ensino e aprendizagem, desenvolve no aluno o valor de confiança. Com o tempo, o aluno transfere esta integração para o seu meio social. A afetividade do professor implica na aprendizagem que provavelmente é um mecanismo que tem influência sobre a motivação e o interesse por parte dos alunos no processo de aprender. Quando o professor valoriza a proposta educacional pensando nos seus alunos e envolvendo a afetividade, poderá atingir a participação imediata por parte dos alunos que sentem que podem confiar no professor.

Assim, este trabalho se propõe a identificar as concepções de professores a respeito da importância da afetividade na aprendizagem. Também é objeto deste estudo identificar as habilidades sociais de professores e relacionar este repertório comportamental às suas concepções sobre aprendizagem. 


\section{Método}

Participantes

Participaram 70 professores que atuavam do $6^{\circ}$ ao $9^{\circ}$ ano do ensino fundamental e do $1^{\circ}$ ao $3^{\circ}$ ano do ensino médio em escolas privadas do município de Nilópolis, em que 41 eram do gênero feminino e 29 do gênero masculino, com idades de 18 a 47 anos.

\section{Instrumentos}

Foram utilizados para a coleta de dados os instrumentos: (a) Questionário para coleta de dados sociodemográficos; (b) Questionário composto por quatro perguntas abertas sobre relação afetiva professor-aluno. Todas as perguntas estão relacionadas à interação afetiva professor-aluno no processo da aprendizagem e com propósito de colher informações sucintas e diretas dos professores relativas ao aluno no contexto escolar; (c) Inventário de Habilidades Sociais (IHS - Del Prette e Del Prette, 2001). É um questionário de autorrelato composto de 38 itens agrupados em cinco fatores: (1) Assertividade - itens 7, 12, 11, 16, 5, 20, 15, 14, 21, 1 e 29; (2) Autoafirmação na expressão de sentimentos positivos - itens $28,35,6,3,10$, 30 e 8; (3) Conversação e a desenvoltura social - itens 36, 17, 24, 19, 13, 37 e 22; (4) Autoexposição a desconhecidos ou a situações novas - itens 9, 26 e 23; (5) Autocontrole da agressividade a situações aversivas - itens 18, 31 e 38. Os itens 2, 4, 25, 27, 32, 33 e 34 não entram nos fatores e nos itens $2,8,9,13,17,18,19,22,23,24,26,34,36$ e 37 a pontuação é posteriormente invertida para a obtenção do escores. De acordo com as instruções, o respondente terá que preencher uma folha situada no fim dos itens. Trata-se de uma escala tipo Likert de cinco pontos variando entre "nunca ou raramente" a "sempre ou quase sempre".

\section{Procedimentos}

Para a coleta dos dados foram aplicados os instrumentos: (a) Questionário de dados sociodemográficos; (b) Questionário de perguntas abertas, em que a aplicação foi individual e sem tempo limite; (c) Inventário de Habilidades Sociais. Os locais da aplicação dos instrumentos foram em salas disponibilizadas pelas instituições de ensino. Todos os participantes assinaram termo de consentimento livre e esclarecido.

\section{Apresentação e discussão dos resultados}

Ao ser analisada a posição em percentis do resultado total do IHS, percebeu-se que 67 (95,71\%) professores apresentam um repertório bastante elaborado de habilidades sociais (HS), ou seja, a grande maioria está acima da média, ficando apenas três $(4,29 \%)$ professores entre os intervalos do repertório bastante elaborado de IHS e bom repertório de IHS acima da média.

0 estudo de cada fator do IHS é identificado na Tabela 1, o que permitiu caracterizar a amostra de acordo com a habilidade social a que se refere.

Sendo assim, o Fator 1 reúne itens nos quais se avalia a capacidade do respondente em comunicar-se (perguntar, conversar, pedir) e de defender seus direitos de afirmação (expor ponto de vista, discordar, discutir), ou seja, habilidades assertivas de comunicação. De um total de 70 professores respondentes nesta amostra, 57 (81,43\%) apresentaram no Fator 1, percentis entre 75 e 100 mostrando possuírem um repertório bastante elaborado para o enfrentamento e autoafirmação com risco, seguidos de $12(17,14 \%)$ professores com percentis entre 50 e 75, com um bom repertório (acima da média). Entre o intervalo de 25 e 50 somente um (1,43\%)

Tabela 1 - Análise e interpretação de fatores

\begin{tabular}{|c|c|c|c|c|c|c|c|c|c|c|c|}
\hline Interpretação & $\begin{array}{c}\text { Posição em } \\
\text { percentis }\end{array}$ & $\begin{array}{c}\text { Fator } \\
1 \\
\end{array}$ & Total & $\begin{array}{c}\text { Fator } \\
2\end{array}$ & Total & $\begin{array}{c}\text { Fator } \\
3\end{array}$ & Total & $\begin{array}{c}\text { Fator } \\
4\end{array}$ & Total & $\begin{array}{c}\text { Fator } \\
5 \\
\end{array}$ & Total \\
\hline \multirow{8}{*}{$\begin{array}{l}\text { Repertório bastante } \\
\text { elaborado de HS }\end{array}$} & 100 & 11 & \multirow{7}{*}{57} & 16 & \multirow{7}{*}{50} & 09 & \multirow{7}{*}{58} & 07 & & 10 & \multirow{7}{*}{45} \\
\hline & 99 & 07 & & 11 & & 07 & & 05 & & 05 & \\
\hline & 97 & 05 & & 04 & & 07 & & 07 & & 07 & \\
\hline & 95 & 05 & & 05 & & 11 & & 08 & 53 & 03 & \\
\hline & 90 & 08 & & 02 & & 07 & & 03 & & 06 & \\
\hline & 85 & 08 & & 04 & & 04 & & 08 & & 06 & \\
\hline & 80 & 09 & & 04 & & 11 & & 07 & & 05 & \\
\hline & 75 & 04 & & 04 & & 02 & & 08 & & 03 & \\
\hline
\end{tabular}


Tabela 1 - Análise e interpretação de fatores

\begin{tabular}{|c|c|c|c|c|c|c|c|c|c|c|c|}
\hline Interpretação & $\begin{array}{c}\text { Posição em } \\
\text { percentis }\end{array}$ & $\begin{array}{c}\text { Fator } \\
1 \\
\end{array}$ & Total & $\begin{array}{c}\text { Fator } \\
2 \\
\end{array}$ & Total & $\begin{array}{c}\text { Fator } \\
3 \\
\end{array}$ & Total & $\begin{array}{c}\text { Fator } \\
4 \\
\end{array}$ & Total & $\begin{array}{c}\text { Fator } \\
5 \\
\end{array}$ & Total \\
\hline \multirow{4}{*}{$\begin{array}{l}\text { Bom repertório de } \\
\text { HS (acima da média) }\end{array}$} & 70 & 05 & \multirow{4}{*}{12} & 04 & \multirow{4}{*}{10} & 07 & \multirow{4}{*}{12} & 08 & \multirow{4}{*}{14} & 07 & \multirow{4}{*}{13} \\
\hline & 65 & 04 & & 03 & & 03 & & 02 & & 04 & \\
\hline & 60 & 01 & & 02 & & 01 & & 03 & & 02 & \\
\hline & 55 & 02 & & 01 & & 01 & & 01 & & - & \\
\hline Repertório Mediano & 50 & - & & - & & - & & - & & - & \\
\hline \multirow{5}{*}{$\begin{array}{c}\text { Bom repertório } \\
\text { de HA (abaixo da } \\
\text { média) }\end{array}$} & 45 & 01 & \multirow{5}{*}{01} & 06 & \multirow{5}{*}{10} & - & \multirow{5}{*}{ - } & 02 & \multirow{5}{*}{03} & 01 & \multirow{5}{*}{03} \\
\hline & 40 & - & & 04 & & - & & 01 & & 02 & \\
\hline & 35 & - & & - & & - & & - & & - & \\
\hline & 30 & - & & - & & - & & - & & - & \\
\hline & 25 & - & & - & & - & & - & & - & \\
\hline \multirow{6}{*}{$\begin{array}{c}\text { Indicação para } \\
\text { treinamento em HS }\end{array}$} & 20 & - & & - & & - & & - & & - & \multirow{6}{*}{09} \\
\hline & 15 & - & & - & & - & & - & & 03 & \\
\hline & 10 & - & & - & & - & & - & & 06 & \\
\hline & 05 & - & & - & & - & & - & & - & \\
\hline & 03 & - & & - & & - & & - & & - & \\
\hline & 01 & - & & - & & - & & - & & - & \\
\hline $\begin{array}{l}\text { Número válido de } \\
\text { respondentes }\end{array}$ & & 70 & & 70 & & 70 & & 70 & & 70 & \\
\hline
\end{tabular}

Fonte: Dados da pesquisa

professor apresentou um repertório mediano com a posição em percentil de 45 . No último intervalo de percentis de 0 e 25 indicou que nenhum dos respondentes foram indicados para treinamento para HS.

0 Fator 2 agrupa itens relacionados à autoafirmação na expressão de sentimentos positivos: "agradecer elogios", "elogiar familiares", "participar de conversação", "expressar sentimento positivo". Neste fator, $50(71,43 \%)$ dos professores respondentes apresentaram-se com percentis entre $75 \mathrm{e}$ 100 , representando um repertório bastante elaborado; em seguida, 10 (14,28\%) professores apresentaram um bom repertório (acima da média), com percentis entre 50 e 75. Um bom repertório (abaixo da média) foi representado por $10(14,28 \%)$ dos professores respondentes, com percentis entre 25 e 50 . Neste fator 2 , assim como no fator 1 , entre os intervalos de percentis de 0 e 25 , não foi indicado nenhum dos respondentes para treinamento em HS.

Os itens agrupados no Fator 3, avaliam habilidades assertivas (defesa de direitos pessoais, expressão de sentimentos) em situações desfavoráveis, nas quais existe um risco de reação indesejável por parte do interlocutor, já que o respondente estaria em desacordo com ele ou contrariando-o. Encontra-se neste fator, 58 $(82,85 \%)$ dos professores com percentis entre 75 e 100 , apresentando um repertório bastante elaborado. Dos professores respondentes $12(17,14 \%)$ apresentam-se com um bom (acima da média) com percentis entre 50 e 75 . Nos outros intervalos de percentis de 25 e 50 e no de 0 e 25 não houve respondentes.

0 Fator 4 inclui itens nos quais as situações descritas estão relacionadas à autoexposição a desconhecidos e situações novas. Demandam desenvoltura social dos respondentes, desembaraço para se manifestar em ocasiões usualmente constrangedoras (fazer perguntas e pedir favores a desconhecidos). Apresentaram um repertório bastante elaborado para autoexposição a desconhecidos e situações novas, $53(75,71 \%)$ professores respondentes, com percentis entre 75 e 100; um bom repertório (acima da média), 14 (20\%) professores, com percentis entre 50 e 75; um bom repertório (abaixo da média), três $(4,28 \%)$ professores com percentis entre 25 e 50 e nos intervalos de 0 e 25 não houve nenhuma indicação para treinamento em HS.

O Fator 5, denominado "autocontrole da agressividade", reúne itens que supõem reação a estimulações 
potencialmente estressantes (críticas e brincadeiras/ gozações), demandando controle da raiva e agressividade. Neste fator, $45(64,28 \%)$ dos professores apresentam repertório bastante elaborado com percentis entre 75 e 100; 13 (18,57\%) professores com bom repertório (acima da média), percentis entre 50 e 75; $3(4,28 \%)$ professores com bom repertório (abaixo da média), percentis entre 25 e 50 e nove $(12,86 \%)$ professores com indicação para treinamento em HS, percentis entre 0 e 25 .

Diante das análises dos resultados de cada fator, verifica-se que o repertório de habilidades sociais apresentado pelos professores demonstra capacidades de perguntar, conversar, pedir, expor pontos de vista, discordar, discutir, utilizando as habilidades assertivas da comunicação. Expressar sentimentos positivos, como carinho, bem-estar, felicidade e de agrado com elogios, agradecimento, aprovação. Utilizar a conversação e a desenvoltura social para um melhor desempenho profissional.

Não foram encontradas diferenças significativas entre os fatores (Tabela 2).

Análise do Questionário sobre as Concepções Implícitas de Professores

Tabela 2 - Distribuição dos descritores da questão 1

\begin{tabular}{ccc}
\hline & Descritores & $\begin{array}{c}\text { Número de } \\
\text { citações }\end{array}$ \\
\hline $\begin{array}{c}\text { Relação afetiva } \\
\text { explícita }\end{array}$ & Amizade & 39 \\
& Amor & 03 \\
& Carinho & 05 \\
& Afetividade & 07 \\
Total & & 54 \\
Relação afetiva & Respeito & 21 \\
não explícita & Confiança & 02 \\
& Diálogo & 02 \\
\hline Total & & 25 \\
Não pertinentes & & 16 \\
\hline
\end{tabular}

Fonte: Dados da pesquisa.

A partir das respostas emitidas foram estabelecidas duas categorias: respostas relacionadas a uma relação afetiva explícita, ou seja, em que os respondentes claramente descrevem sua relação interpessoal como sendo determinada por sentimentos de afetividade e respostas relacionadas a uma relação afetiva não explícita, ou seja, existe um relacionamento interpessoal, porém a afetividade não é claramente abordada. Para a primeira categoria, encontrou-se um total de $54(77,14 \%)$ das respostas sendo $72,22 \%$ de citações vinculadas à amizade, 5,55\% relacionadas ao amor, $9,26 \%$ ao carinho e $12,96 \%$ a relacionamentos interpessoais afetivos. Quanto à segunda categoria, encontrou-se um total de $25(35,71 \%)$ das respostas sendo $84 \%$ de citações de respeito, $8 \%$ de relações baseadas na confiança e $8 \%$ baseadas no diálogo. Encontraram-se ainda 16 respostas não pertinentes (Tabela 3).

Tabela 3 - Distribuição dos descritores da questão 2

\begin{tabular}{|c|c|c|c|}
\hline & & Descritores & $\begin{array}{c}\text { Número de } \\
\text { citações }\end{array}$ \\
\hline \multirow{6}{*}{$\begin{array}{l}\text { Relação afetiva } \\
\text { explícita }\end{array}$} & \multirow{6}{*}{ Sim } & Mostrar amizade & 14 \\
\hline & & $\begin{array}{l}\text { Conversar / } \\
\text { Dialogar }\end{array}$ & 20 \\
\hline & & Tentar ajudar & 15 \\
\hline & & Ficar atento & 03 \\
\hline & & Orientar & 05 \\
\hline & & Dar atenção & 01 \\
\hline Total & & & 58 \\
\hline $\begin{array}{l}\text { Relação afetiva } \\
\text { não explícita }\end{array}$ & Não & Falta de Tempo & 01 \\
\hline Total & & & 01 \\
\hline Não pertinentes & & & 11 \\
\hline
\end{tabular}

Fonte: Dados da pesquisa.

As mesmas categorias foram estabelecidas para todas as perguntas. Para a primeira categoria encontrou-se um total de $58(82,85 \%)$ das respostas, sendo $24,13 \%$ de citações vinculadas a mostrar amizade, $34,48 \%$ relacionadas a conversar/dialogar, $25,86 \%$ a tentar ajudar, $5,17 \%$ a ficar atento, $8,62 \%$ a orientar e 1,72\% a dar atenção. Quanto à segunda categoria, apenas uma resposta foi encontrada relacionada à falta de tempo. Encontraram-se ainda 11 respostas não pertinentes.

Para a primeira categoria encontrou-se um total de $32(45,71 \%)$ das respostas sendo $25 \%$ de citações vinculadas à aproximação, 21,87\% relacionadas à afetividade, $15,62 \%$ relacionadas ao amor, $12,5 \%$ ao prazer e $25 \%$ a relacionamentos e interação pessoal. Quanto à segunda categoria, encontrou-se um total de 29 (41,42\%) das respostas sendo $65,51 \%$ de 
relações baseadas na confiança, $14,13 \%$ baseadas no diálogo e 20,68\% baseadas no diálogo. Encontraram-se ainda nove respostas não pertinentes (Tabela 4).

Tabela 4 - Distribuiç̃ão dos descritores da questão 3

\begin{tabular}{|c|c|c|c|}
\hline & & Descritores & $\begin{array}{l}\text { Número de } \\
\text { citações }\end{array}$ \\
\hline \multirow{5}{*}{$\begin{array}{l}\text { Relação afetiva } \\
\text { explícita }\end{array}$} & Sim & Aproximação & 08 \\
\hline & & Afetividade & 07 \\
\hline & & Amor & 05 \\
\hline & & Prazer & 04 \\
\hline & & Interação & 08 \\
\hline Total & & & 32 \\
\hline \multirow{3}{*}{$\begin{array}{l}\text { Relação afetiva } \\
\text { não explícita }\end{array}$} & Sim & Confiança & 19 \\
\hline & & Diálogo & 04 \\
\hline & & Respeito & 06 \\
\hline Total & & & 29 \\
\hline Não pertinentes & & & 09 \\
\hline
\end{tabular}

Fonte: Dados da pesquisa.

Tabela 5 - Distribuição dos descritores da questão 4

\begin{tabular}{|c|c|c|c|}
\hline & & Descritores & $\begin{array}{l}\text { Número de } \\
\text { citações }\end{array}$ \\
\hline \multirow[t]{5}{*}{$\begin{array}{l}\text { Relação afetiva } \\
\text { explícita }\end{array}$} & Sim & $\begin{array}{l}\text { Temperamento } \\
\text { Agressivo do Pro- } \\
\text { fessor }\end{array}$ & 08 \\
\hline & & Timidez do Aluno & 01 \\
\hline & & $\begin{array}{l}\text { Dificuldade de Ex- } \\
\text { pressão por parte } \\
\text { do Professor }\end{array}$ & 15 \\
\hline & & $\begin{array}{l}\text { Atitudes Negativas } \\
\text { do Professor }\end{array}$ & 18 \\
\hline & & $\begin{array}{l}\text { Falta de Aproxima- } \\
\text { ção do Professor }\end{array}$ & 08 \\
\hline Total & & & 50 \\
\hline \multirow{2}{*}{$\begin{array}{l}\text { Relação afetiva } \\
\text { não explícita }\end{array}$} & Sim & Falta de Diálogo & 05 \\
\hline & & $\begin{array}{l}\text { Por rotular a dis- } \\
\text { ciplina }\end{array}$ & 05 \\
\hline Total & & & 10 \\
\hline Não pertinentes & & Não & 10 \\
\hline
\end{tabular}

Fonte: Dados da pesquisa.
Para a primeira categoria, encontrou-se um total de $50(71,42 \%)$ das respostas sendo $16 \%$ de citações vinculadas ao temperamento agressivo do professor, $2 \%$ relacionadas à timidez do aluno, 30\% à dificuldade de expressão por parte do professor, $36 \%$ à atitudes negativas do professor e $16 \%$ relacionadas à falta de aproximação do professor. Quanto à segunda categoria, encontrou-se um total de 10 $(14,28 \%)$ das respostas sendo $50 \%$ de citações em relação à falta de diálogo e $50 \%$ baseadas por rotular a disciplina. Encontraram-se ainda 10 respostas não pertinentes.

Por fim verificou-se, com a utilização da ANOVA, a relação existente entre as Habilidades Sociais, mensuradas com o IHS e as Concepções Implícitas de Professores. $\mathrm{O}$ resultado obtido $(\mathrm{F}=2.125 ; \mathrm{p}=0.0896)$ indicou que as habilidades sociais não diferiam significativamente em cada uma as classificações das concepções implícitas de professores (Tabela 5).

\section{Discussão}

Os resultados apontam que $95,71 \%$ dos professores apresentam um repertório bastante elaborado de HS; a grande maioria dos professores estão acima da média. Possuem repertório bastante elaborado de habilidades sociais, ou seja, são profissionais que utilizam a desenvoltura social como instrumento para desenvolver o trabalho de mediadores do conhecimento ao aluno. Resultados semelhantes foram encontrados na pesquisa realizada por Soares et al. (2009) na qual verificaram que as habilidades sociais do professor compõem um sistema facilitador e um meio de interação importante para inserir o indivíduo na sociedade por meio da aprendizagem. Observaram também que, para alcançar um bom desempenho nos relacionamentos interpessoais entre professores e alunos, um ambiente democrático colabora para uma boa interação e favorece o processo ensino-aprendizagem.

Outros trabalhos também têm evidenciado que o bom desempenho interpessoal entre professores e alunos é fundamental para o estabelecimento de um ambiente de aprendizagem produtivo. Tunes, Tacca e Bartholo Jr. (2005) argumentam que a aquisição do conhecimento escolar é um processo dinâmico entre professor e aluno que desempenham funções interativas resultando em atividades que envolvem a aprendizagem. 0 professor possibilita ao aluno 
maneiras de pensar, uma vez que é em grande parte responsável pelo processo de aquisição do conhecimento e crescimento pessoal de seus alunos. Portanto o professor deve ter a desenvoltura de estabelecer diálogos com os alunos com a finalidade de formar vínculos de confiança mútua, tendo o papel de mediador no processo do conhecimento dos seus alunos.

Duarte (2004), em um estudo realizado em um curso de preparação para professores de inglês da rede pública de São Paulo e a fim de gerar um ambiente propício à aprendizagem, promoveu discussões em torno da jornada de trabalho desses professores, em que são submetidos a várias situações, como problemas interpessoais e afetivos, envolvidos no processo de ensino e aprendizagem. Nesse curso, foi proposto aos professores três atitudes que poderiam desenvolver em sala de aula: congruência, aceitação ou consideração positiva e empatia. A congruência parte do ponto de que o indivíduo precisa ter plena consciência da sua existência como um todo, no qual possa perceber os sentimentos do outro permitindo uma boa comunicação e convivência interpessoal. Já a aceitação ou consideração positiva é quando um indivíduo acredita que o outro pode ser digno de confiança e que através da individualidade o outro é um ser incondicional. A empatia são atitudes que permitem o indivíduo se colocar no lugar do outro em diversas situações, no qual veja e sinta pelo ponto de vista do outro. No entanto, a autora ressalta que esses comportamentos terão que ser equilibrados pelo professor para que não pareçam falsos. Este estudo atinge o seu objetivo, na medida em que mostra que as ações dos professores podem ser modificadas a partir do seu autoconhecimento e o seu próprio desejo de mudar diante dos problemas que surgem no contexto escolar.

Conduzindo uma pesquisa com 50 professores do ensino médio e 50 professores do ensino universitário do Estado do Rio de Janeiro, Naiff, Soares, Azamor, Almeida e Baldez (2007) tiveram como objetivo identificar a importância atribuída às habilidades do bom professor no contexto escolar. Três categorias de habilidades foram identificadas: habilidades relacionais, que envolve a interação do professor com o aluno possibilitando uma aprendizagem eficaz; habilidades profissionais, que indica a prática do professor no cotidiano escolar; habilidades inovadoras, em que o aluno exige do professor respostas criativas e dinâmicas na prática do ensino. Concluíram que os professores acreditam que as habilidades docentes são norteadas pelos desafios impostos por realidades que privilegiam a competência interpessoal e a busca por resultados acadêmicos.

O comportamento interpessoal é um aliado do professor para a aprendizagem do aluno. Sendo assim, o desenvolvimento das habilidades sociais na prática profissional da docência possui um aspecto de interação entre professor e aluno que pode ajudar na aquisição do conhecimento. Com base nesta perspectiva Del Prette, Del Prette, Torres e Pontes (1998) realizaram uma pesquisa com seis professores entre 24 e 47 anos, para verificar a influência de um Programa de Desenvolvimento Interpessoal Profissional (PRODIP) após a intervenção nesses profissionais. A intervenção teve como objetivo desenvolver as habilidades interpessoais dos professores para que tivessem uma melhor interação social com e entre os alunos. Nesse contexto, o exercício da prática de promover a aprendizagem deve ser norteado pela valorização e esforço tanto por parte do professor, quanto do aluno. Segundo Del Prette e Martini (2002), o professor deve valorizar o esforço de ambos, seu e do aluno, diversificando a capacidade do aluno de enfrentar os desafios e dificuldades escolares, contribuindo para o desenvolvimento, aprendizagem e motivação do aluno. Os professores deverão ter consciência de que suas crenças influenciam no desempenho dos alunos, uma vez que são mediadores da aprendizagem. As crenças positivas dos professores contribuem no conhecimento eficaz do aluno (Del Prette \& Martini, 2002).

Na transmissão do conhecimento, em que o professor é um facilitador da aprendizagem para o aluno, também são possibilitados meios para a interação do aluno com a sociedade e cultura de que faz parte. Silva (2005) ressalta a importância da relação professor/aluno ser norteada pela afetividade e empatia, na qual o aluno aprende e compreende seus deveres e responsabilidades sociais por meio das diversas experiências interpessoais que vivencia no seu cotidiano escolar. Aprende a respeitar e ser respeitado em sala de aula de acordo com a relação que estabelece com o professor e colegas. Para Silva, o conhecimento é frequentemente construído quando o aluno interage com o professor, criando, com ele, o contexto para a interação. Nessa interação, o conhecimento é produzido coletivamente e partilhado entre os participantes. Portanto o conhecimento pode ser um sistema cooperativo de resolução de problemas, significados e compreensões discutidos 
e negociados, que regulam comportamentos que estão envolvidos no processo socioemocional.

0 processo socioemocional que envolve a relação professor/aluno na aquisição do conhecimento vai além da transmissão do saber, uma vez que estão presentes sentimentos, como o afeto e valores, proveniente das experiências em sala de aula, no qual permite que o professor conheça seu aluno favorecendo uma aprendizagem mais profícua. No entanto, na profissão de professor é lançado um desafio para ser um agente interessado efetivamente pelos problemas que surgem no ambiente escolar, como problemas interpessoais e afetivos (Escaraboto, 2007).

Quanto aos fatores que envolvem as concepções dos professores, foi verificado que a maioria dos professores $(77,14 \%)$ concebem a amizade e respeito como fatores afetivos na relação professor/aluno e atribuem importância da afetividade na aprendizagem do aluno. Portanto os professores reconhecem que a interação no contexto escolar possibilita a aprendizagem. Segundo Ribeiro, Jutras e Louis (2005), os componentes afetivos são necessários para a intervenção do professor na prática educativa. A educação escolar não se separa dos componentes sociais que envolvem a aprendizagem, uma vez que as relações pedagógicas implicam a mediação do professor com o aluno para despertar a motivação das atividades escolares. É a partir de uma relação afetiva entre professor e aluno que as aulas poderão ser mais produtivas. Nelas, os alunos percebem quando o professor realmente deseja ensinar-lhes mais do que os livros ensinam (Leite \& Tagliaferro, 2005).

Diante dos resultados, pode-se constatar que, na aprendizagem, o papel do professor não é somente de mediador do conhecimento mas também aquele que representa uma figura em que os alunos possam confiar, respeitar e admirar. Contudo o professor precisa conquistar esses atributos do aluno transmitindo a afetividade na prática da aprendizagem e acreditando na capacidade de aprender do aluno. Sendo assim, percebe-se, nos resultados apresentados na Tabela 3, que os professores $(34,48 \%)$ tentam conversar com os alunos em situações em que precisam de apoio emocional, buscam a interação e a confiança do aluno, na medida em que o professor interage com o aluno, desperta no aluno a motivação em aprender. Portanto, na escola, o aluno busca motivações que envolvem seu processo de desenvolvimento pessoal. Assim, o professor tem como desafio ver no aluno a sua totalidade para que seja um mediador da aprendizagem. No contexto educacional, é necessário que se tenha uma interação com base em confiança conquistada pelo professor em relação ao aluno (Mahoney \& Almeida, 2005).

A concepção que os professores têm sobre a afetividade ser de importante ajuda na aprendizagem é mostrado na Tabela 4, em que os resultados indicam que os professores concordam com essa afirmativa e que a maioria deles $(65,51 \%)$ têm a concepção de que a afetividade na aprendizagem é uma relação não explícita de confiança. Neste contexto, quando o professor obtém a confiança do aluno, a possibilidade de aprendizagem acontecer é grande, pois o aluno sente no professor a transmissão do afeto, no qual desperta nele a motivação em aprender (Mahoney \& Almeida, 2005). 0 afeto tem uma ligação com a subjetividade e a cultura que faz parte da humanidade, e é resgatado a partir de trabalhos educativos e artísticos vistos em ambiente escolar. 0 afeto possibilita a transmissão do saber ao aluno e é o que mobiliza o outro para que seja um processo contínuo. Na medida em que a afetividade pode influenciar no processo de ensino/aprendizagem, também implica o envolvimento do professor com a subjetividade do aluno. Com isso, o professor pode enxergar nas dificuldades do aluno uma possibilidade de aprendizagem, depositando nele a confiança de que é capaz de aprender, o que possibilita no aluno o desejo de aprender (Cunha, 2008).

Nessa perspectiva, os professores desta pesquisa foram indagados se já haviam identificado, nos alunos, problemas de aprendizagem cujas origens fossem questões interpessoais entre professor/aluno. Os resultados vistos na Tabela 5 indicam que 36\% dos professores entendem que atitudes negativas por parte do professor podem dificultar a aprendizagem do aluno, bem como para $30 \%$ deles a dificuldade de expressão por parte do professor também pode ser um mecanismo que dificulta a aprendizagem do aluno. Tais dados são verificados também nos estudos de Ribeiro, Jutras e Louis (2005), em que constataram que professores possuem representações afetivas positivas para a melhoria da aprendizagem, porém os professores não escondem que há práticas autoritárias e uso de agressões de várias naturezas por parte dos professores em relação aos alunos que pode prejudicar o aprendizado.

Diante dos resultados encontrados nessa pesquisa, pode-se verificar que a afetividade está implícita nas respostas dos professores, contudo não há relação 
entre as habilidades sociais mensuradas e as concepções implícitas de professores. Os professores muito habilidosos, ou seja, assertivos, desenvoltos, com controle de sua agressividade e afetivos demonstram provavelmente sua competência social em sala de aula e entendem que a afetividade é importante para a aprendizagem, porém essas variáveis não se relacionam.

\section{Considerações finais}

Este estudo procurou traçar um perfil do professor habilidoso socialmente sobre a perspectiva da afetividade na mediação do conhecimento entre ele e o aluno. Os resultados mostram que os professores sabem da importância de serem afetuosos com aqueles que estão na busca do saber, e com aqueles que expressam dificuldades na aprendizagem. Visto que a maioria dos professores tem em seu comportamento repertórios bastante elaborados de habilidades sociais para enfrentar variadas situações com seus alunos, bem como com os pais dos alunos e outros funcionários da escola, os professores acreditam que a interação a partir da afetividade pode ajudar ambos, professor e aluno, na aquisição do conhecimento e a enfrentar problemas interpessoais que possam surgir no contexto escolar.

As relações interpessoais no contexto escolar envolvem inúmeras variáveis, que propiciam ao aluno um bom processo de aprendizagem, ou seja, inúmeras situações que fazem parte do processo de ensino-aprendizagem envolvem o aluno em sala de aula, principalmente nas relações interpessoais entre os professores e alunos, em que são construídos vínculos com a aprendizagem.

Portanto este estudo pretendeu contribuir para o entendimento da afetividade no processo de mediação do conhecimento do professor para o aluno. No entanto a afetividade no contexto escolar ainda é um campo em desenvolvimento. 0 professor tem em seu repertório comportamental habilidades sociais bastantes elaboradas e sabe que, por meio da afetividade, pode atingir a motivação do aluno que aprende.

\section{Referências}

Almeida, L. S. (2002). Facilitar a aprendizagem: Ajudar os alunos a aprender e a pensar. Psicologia Escolar e Educacional, 6(2), 155-165.
Assmann, H. (2000). Reencantar a Educação: Rumo à Sociedade Aprendente (4a ed.) Petrópolis: Vozes.

Cunha, E. (2008). Afeto e Aprendizagem: Relações de amorosidade e saber na prática pedagógica. Rio de Janeiro: Wak.

Del Prette, Z., Del Prette, A., Garcia, F., Silva, A., \& Puntel, L. (1989). Habilidades sociais do professor em sala de aula: um estudo de caso. Psicologia: Reflexão e Crítica, 11(3), 591-603.

Del Prette, Z., Del Prette, A., \& Correia, M. F. B. (1992). Competência social: Um estudo comparativo entre alunos de Psicologia, Serviço Social e Engenharia Mecânica. Psicólogo Escolar: Identidade e Perspectivas, $2,382-384$.

Del Prette, A., \& Del Prette, Z. (1997). Habilidades sociais e construção de conhecimento em contexto escolar. In: D. R. Zamignani (Org.). Sobre comportamento e cognição. Santo André: ARBytes.

Del Prette, A., Del Prette, Z., Torres, A., \& Pontes, A. (1998). Efeitos de uma intervenção sobre a topografia das habilidades sociais de professores. Psicologia Escolar e Educacional, 2(1), 11-22.

Del Prette, A., \& Del Prette, Z. (2001). Inventário de Habilidades Sociais (IHS-Del-Prette): Manual de aplicação, apuração e interpretação. São Paulo: Casa do Psicólogo.

Del Prette, Z., \& Martini, M. L. F. P. (2002). Atribuições de causalidade para o sucesso e o fracasso escolar dos seus alunos por professores do ensino fundamental. Interação em Psicologia, 6(2), 149-156.

Del Prette, A., \& Del Prette, Z. (Org.). (2003). Habilidades sociais, desenvolvimento e aprendizagem: Questões conceituais, avaliação e interpretação. Campinas: Alínea.

Del Prette, Z., Paiva, M., \& Del Prette, A. (2005). Contribuições do referencial das habilidades sociais para uma abordagem sistêmica na compreensão do processo de ensino-aprendizagem. Interações - Estudos e Pesquisa em Psicologia, 10(20), 57-72.

Duarte, V. C. (2004). Relações interpessoais: professor e aluno em cena. Psicologia Educacional, 19(1), 119-142.

Escaraboto, K. M. (2007). Sobre a importância de conhecer e ensinar. Psicol - USP, 18(4), 133-146. 
Garcia, M. M. A., Hypolito, A. M., \& Vieira, J. S. (2005). As identidades docentes como fabricação da docência. Educação e Pesquisa, 31(1), 45-56.

Leite, S., \& Tagliaferro, A. (2005). A afetividade na sala de aula: Um professor inesquecível. Psicologia Escolar e Educação, 9(2), 247-260.

Loos, H., \& Sant'Ana, R. S. (2007. Jul./dez.). Cognição, afeto e desenvolvimento humano: A emoção de viver e a razão de existir. Educar em Revista, 30(1), 165-182.

Mahoney, A., \& Almeida, L. (2005). Afetividade e processo ensino-aprendizagem: Contribuição de Henri Wallon. Psicologia da Educação, 20(1), 11-30.

Marturano, E. M., \& Loureiro, S. R. (2003). O desenvolvimento socioemocional e as queixas escolares. In: Del Prette, A., \& Del Prette, Z. A. P. (Org.). Habilidades sociais, desenvolvimento e aprendizagem: Questões conceituais, avaliação e intervenção (pp. 259-291). Campinas: Alínea.

Naiff, L. A. M., Soares, A. B., Azamor, C. R., Almeida, S. A. Cardozo, A., \& Baldez, M. O. (2007). Habilidades do bom professor em debate: representações sociais de professores do ensino médio e do ensino superior no Estado do Rio de Janeiro. Anais do XIV Encontro Nacional da ABRAPSO, UERJ.
Ribeiro, M. L., Jutras, F.; \& Louis, R. (2005). A análise das relações sociais de afetividades na relação educativa. Psicologia da Educação, 20(1), 31-54.

Silva, J. P. S. (2005). A relação Professor/Aluno no processo de ensino e aprendizagem. Revista Espaço Acadêmico, 52. Recuperado em 15 maio 2010, em http:// www.espacoacademico.com.br/052/52pc_silva.htm

Soares, A. B., Naiff, L. Cardozo, A., Baldez, M., \& Fonseca, L. (2009). As habilidades sociais e variáveis sócio-demográficas de professores. Psicologia: Teoria e Prática, 11(1), 35-49.

Tunes, E., Tacca, M. C. V. R., \& Bartholo Jr., R. S. (2005). O professor e o ato de ensinar. Caderno de Pesquisa, 35(126), 689-698.

Wallon, H. (1996). A atividade proprioplástica. In J. NadelBrulfert \& M. J. G. Werebe. Antologia. São Paulo: Ática. 
